\title{
Incorporating sustainable development principles into building design: a review from a structural perspective including case study
}

\author{
Dane Miller and Jeung-Hwan Doh*,† \\ Griffith School of Engineering, Griffith University, Gold Coast Campus, Queensland 4222, Australia
}

\section{SUMMARY}

The incorporation of sustainable development (SD) principles into all industries is increasingly important. The contribution of the building industry to a wide range of environmental impacts is extensive with the construction, operation and maintenance of buildings accounting for approximately $50 \%$ of all energy usage and anthropogenic greenhouse gas $(\mathrm{GHG})$ emissions globally. In the building design process, structural engineers play a limited role in the sustainability of a design. The decisions on the incorporation of such aspects are usually at the mercy of the architect and client. A literature review was conducted to record and present the variability in research on issues directly related to the environmental performance of structures. There are inconsistencies in the published contribution of embodied energy (EE) and proportion of life cycle energy usage in structures. Outcomes demonstrate that due to this variability, environmental performance of structures is difficult to validate. A systematic approach beginning with standardized calculation procedure and database generation for $\mathrm{EE}$ of building materials is essential for practitioners to deliver sustainable structural designs. An analysis of a typical concrete office structure indicates potential benefits through the use of quantifiable environmental performance measures, delivering efficient solutions. Comparisons of slab construction techniques indicate overall EE reductions up to $40 \%$ being achievable. Copyright (C) 2014 John Wiley \& Sons, Ltd.

Received 30 June 2013; Revised 1 June 2014; Accepted 22 June 2014

KEY WORDS: embodied energy; sustainability; sustainable design; structural efficiency

\section{INTRODUCTION}

In the last three decades, sustainability has become increasingly important. Products, services and processors have been labelled 'sustainable', for a number of reasons including the following: marketability, cost efficiency and reduced environmental impacts. When a product, service or process is sustainable, there are undisputed benefits. Practically however, there often exists a disparity between such claims and quantifiable or qualifiable sustainability.

In the building industry, sustainable development (SD), sustainable design, ecologically sustainable design, green buildings, eco-development and numerous other descriptive alternatives have been defined, amended, re-defined and assessed. All encompass the same broad goal to produce or maintain buildings economically while upholding social contributions and improving environmental performance - the Triple Bottom Line (TBL) (Spreckley, 1981). The scope by which these are defined however varies significantly, and to date, no single option has conclusively filled the requirements of an SD system. Knowledge has undoubtedly advanced; however, population-driven consumption continues to drive large-scale development related environmental impacts (Kates, 2000; Kates et al., 2005). These factors lead to requirements for assessing and, where appropriate, modifying the way Q2 all stakeholders in the building industry interact to improve overall energy consumption and related environmental impacts.

*Correspondence to: Griffith School of Engineering, Griffith University, Gold Coast Campus, Queensland 4222, Australia.

†E-mail: J.doh@griffith.edu.au 
The construction, operation and maintenance of buildings are estimated to account for approximately $40 \%-50 \%$ of all energy usage and anthropogenic greenhouse gas (GHG) emissions globally (Hasegawa, 2003; Smith, 2005; Asif et al., 2007; Citherlet and Defaux, 2007; Wood, 2007; Dimoudi and Tompa, 2008; Stephan et al., 2011; Dixit et al., 2012; Langston and Langston, 2013; Baek et al., 2013). In Australia to keep pace with growing demand, approximately 30 million tonnes of finished building products are produced each year. Over $56 \%$ of this quantity, by mass, attributed to concrete and a further $6 \%$ to steel (Walker-Morison et al., 2007). In the USA, each year, the development industry consumes over $40 \%$ of all raw stone, gravel and sand material; $25 \%$ of all raw timber; $40 \%$ of energy and 16\% of water (Lippiatt, 1999; Chong et al., 2009). These statistics highlight the potential benefits achievable by the industry, through improved efficiency.

With Australia's population predicted to increase to approximately 35.5 million by the year 2056 (ABS, 2010) and global population estimated to hit 8.9 billion by 2050 (Kates, 2000), anthropogenic pressures driving construction will continue. These pressures influence climate change and global warming with demand driving further environmental impacts associated with all relevant industry supply chains.

The total life cycle energy of a building includes both embodied energy (EE) and operational energy (OE) (Goggins et al., 2010; Dixit et al., 2010; Dixit et al., 2012):

- OE: energy required for a buildings use including heating and cooling, lighting, maintenance and appliance consumption requirements.

- EE: energy sequestered in building materials and processes required for construction.

Building designers generally base decisions on improving operational efficiencies with some even suggesting an original over investment in EE being advantageous where the outcomes are a life cycle energy reduction due to gained operational efficiencies (Ramesh et al., 2010; Crawford, 2011a). With technologies and policies moving toward the adoption of more renewable energy resources and the emergence of zero energy buildings (ZEBs) (Zahedi, 2010; Crawford, 2011b; Marszal and Heiselberg, 2011; Monahan and Powell, 2011; Zuo et al., 2012a), the focus on improvements in these OE efficiencies will shift due to probable reductions of this components contribution to life cycle environmental impacts.

From a structural design perspective, there exists a contradiction in knowledge, with many practitioners confused as to the appropriate context with which to consider the incorporation of environmentally efficient building elements into the design of a given structure. Several sources place varying degrees of importance on different aspects of the design process (Cole, 1999; Treloar et al., 2000; Fay et al., 2000; Dimoudi and Tompa, 2008; Zuo et al., 2012a). The outcome is an industry through which the inclusion of quantifiably environmentally efficient structural design considerations are ancillary to various other building design matters.

The aim of this paper was to provide an overview of the consideration of SD principles into the structural design of buildings. A summary of the contribution of energy use across the life cycle stages of a structure was conducted as well as the estimated EE attributed to these. The published variability in these estimations was discussed to examine the area through which improvements to the adoption of sustainable structural systems are achieved. To highlight the level of savings achievable, a comparative case study was presented.

\section{SUSTAINABLE DEVELOPMENT: A STRUCTURAL ENGINEERING PERSPECTIVE}

\subsection{Sustainable development principles in the building industry}

Authors, academics, politicians and other relevant stakeholders have, since its origin, grappled with the term SD and its precursors. The intention here is not to restate these. For a critical review on the history of SD, refer to Lélé (1991) and Mebratu (1998). The requirement for and pressure on broadly increasing the adoption of sustainable alternatives has been well published (IUCN, 1980; WCED, 1987; IPCC, 2007). Conceptually, SD is idyllic, delivering development by any definition that appropriately and equally benefits economic and social considerations, while concurrently minimizing related 
environmental impacts. SD has however also been described as: 'a contradiction in terms' (O'Riordan, 1985), 'another development truism' (Redclift, 1987), 'elusive' (Goldin and Winters, 1995), 'an oxymoron' (Tryzna, 1995) and 'creatively ambiguous' (Kates et al., 2005). Despite its numerous definitions and concept, SD has remained elusive and regularly had questions asked of its meaningful, quantifiable progress.

Sustainable development principles have been linked with the building industry, with many aspects appropriately considered. The building industry is referred to as the lifeblood of the economy in the developed world. Its contribution to the economic dimension of SD is unquestioned. In the USA, the construction industry is valued at over $\$ 1$ trillion and provides critical infrastructure to support industries while creating over 6.5 million jobs (Chong et al., 2009). In Europe, this industry provides the largest single contribution to employment with over 7.5\% and $9.7 \%$ of the GDP and $47.6 \%$ of the gross fixed capital formation in 1999 (EU, 2001), and these trends continue globally.

The social benefits provided by structurally sound buildings are also significant. They provide good quality indoor living environments, delivering a significant degree of structural integrity, low vibration, a high degree of weather protection, high fire resistance, good thermal resistance and sound acoustic performance (CCAA, 2010).

The same quantifiable benefits are not available when considering environmental impacts. The built environment was identified as the largest single anthropogenic contributor to climate change (Hasegawa, 2003; IPCC, 2007). The construction, operation and maintenance of buildings are estimated to account for approximately $40 \%-50 \%$ of all energy usage and anthropogenic GHG emissions globally (Hasegawa, 2003; Smith, 2005; Asif et al., 2007; Citherlet and Defaux, 2007; Wood, 2007; Dimoudi and Tompa, 2008; Stephan et al., 2011; Dixit et al., 2012; Langston and Langston, 2013; Baek et al., 2013). The environmental impacts of structures are the core TBL principle requiring most attention to achieve meaningful progress on SD in the built environment. Given the significant proportion of the anthropogenic influences on climate change attributed to the development industry and its related environmental impacts, the emphasis on the need to mitigate these cannot be over stated.

\subsection{The structural engineers role}

Engineers play a major role in the design of structures; however, their contribution to the environmental performance is usually negligible due to the OE focus discussed (Paya-Zaforteza et al., 2009; Ramesh et al., 2010; Crawford, 2011a). Many of the factors leading to unnecessary resource use result directly from the inefficient design of buildings and their associated infrastructure (Greene, 2005; Paya-Zaforteza et al., 2009). Structural engineers must, to incorporate SD principles into building design, participate in interdisciplinary teams of professionals representing all three dimensions of the TBL. The two primary changes required for increased adoption of SD are as follows: (a) provide government incentives for sustainable solutions and (b) ensure there are qualified professionals able to deliver these solutions (Greene, 2005). Informed engineers have a professional obligation to broaden the understanding of policymakers, owners and key stakeholders, who may in turn demand sustainable design.

In the current building design process, structural engineers play a limited role in the overall sustainability of a design (Greene, 2005; Paya-Zaforteza et al., 2009). In addition, it has been noted that the OE considerations over a structure's life cycle make it not practical for a designer to predict the effect of structural design decision on environmental performance (Adalberth, 1997b; Mithraratne and Vale, 2004). These attitudes appear to be slowly changing, with many studies presenting the possible importance of the initial investment in EE and design decisions (Thormark, 2002; Sartori and Hestnes, 2007; Dimoudi and Tompa, 2008; Paya-Zaforteza et al., 2009; Baek et al., 2013). Despite improvements in the understanding of long-term building impacts only influenced during design, the operational requirements are still prioritized and generally rest outside the scope of a structural engineers influence.

Environmental performance mechanisms aimed at facilitating the optimization of structural efficiency are lacking, with this contributing to the deficiencies in improved sustainable structures being delivered. In addition, the variability in published environmental performance measures increase uncertainties for practising structural engineers in assessing this aspect.

A number of national and international building ratings systems have been developed in the past decade, focusing primarily on $\mathrm{OE}$ requirements while largely ignoring the initial investment in EE. 
Kua and Wong (2012) highlight these systems as being not without their shortfalls. They present for the primary green building assessment system used in Singapore; $4 \%$ of the possible assessment points attainable are attributed to the carbon footprint of the structure. The authors have briefly evaluated some of the other world leading alternatives. The UK's Building Research Establishment's Environmental Assessment Method, the USA's Leadership in Energy and Environmental Design and the Green Star rating system has been developed by the Green Building Council of Australia all enable the designing structural engineer to influence between $7 \%$ and $11 \%$ of the points attainable under these systems. It is worth noting that while these ratings systems have a valuable role to play, improvements to the structural considerations would contribute to more beneficial outcomes.

\subsection{Barriers to sustainable structural design alternatives}

A review of a number of local and international studies identifies similarities in the barriers restricting the adoption of SD principles in the building industry. These include the following: (a) lack of legislative or standards' frameworks, (b) varying organizational structure, (c) inconsistent political guidance, (d) lack of financial incentive/reward, (e) negative behavioural and cultural attitude, (f) additional financial cost and (g) absence of client demand (Owen, 2001; Hood, 2004; Chong et al., 2009).

Interestingly, most studies do not identify technology as a barrier. Although there is little doubt that technology and methods are available to achieve a more efficient approach than many solutions provided, the authors would contest the existence of technology that truly achieves the long-term objectives of SD.

Hesitation in adopting SD principles remain, linking this reluctance to those barriers identified above as well as the diverse interests of the stakeholders in any given project (Chong et al., 2009). Zuo et al. (2012b) recently noted the adoption and reporting of such factors is increasing. Crawford (2011a) goes on to encourage all stakeholders to play their part in improving this process. No single industry or stakeholder can be left to implement the required change and co-operation required. Engineers Australia (2003) identifies a lack of government leadership in relation to guidance of future legislative direction, which limits the ability of professionals to develop more sustainable solutions.

The built environment has been generally accepted as delivering 'traditional' or 'conventional' and repetitive solutions taking very limited consideration of the SD process (Paya-Zaforteza et al., 2009). The primary focus of the building industry remains the economic pillar of SD and, more specifically, initial capital costs or return on investment. Despite previously studies indicating that SD alternatives can, in the long run, save significant operational and life cycle costs (Adalberth, 1997a; Treloar et al., 2001; Crawford, 2011a), the focus on minimizing construction costs negates the adoption of such approaches.

Projects incorporating SD objectives are perceived to be more difficult than delivering traditional projects. They often require additional skilled professionals, more design iterations, advanced simulation and analysis, higher construction standards, additional construction precautions and the use of relatively new unfamiliar materials (Pulaski et al., 2006). If managed with traditional style, inefficiencies can result in a number of concerns including, most significantly, cost overruns. It is proposed that this inefficient approach is due largely to an incomplete field of educated professionals and lack of appropriate knowledge, government policies and incentives as well as the inconsistencies present in the literature. The optimization of structural systems and improvements in environmental performance do not necessarily equate to increase costs. When suitably educated multidisciplinary teams collaborate to achieve SD outcomes, solutions may be supplied reducing economic outlays.

\subsection{Embodied energy: an environmental assessment method}

There has been increased awareness across the building industry to the environmental impacts of building materials and construction activities; however, the ability to reduce these impacts is currently limited as a result of lacking evidence-based research. Quantifying the environmental performance of structures requires an appropriate measurement unit. Although there is no perfect environmental assessment measure in terms of building materials and structural design, EE has been widely discussed as an appropriate indicator. A report completed by the Commonwealth of Australia (2006) showed that at present, there is no systematic reporting or measurement framework for construction materials in Australia. To date, there remains no national system to complete this task. As a result, significant potential for improvement in assessing the environmental impacts of the building industry remains 
through an appropriate system (Dixit et al., 2010; Crawford, 2011a; Dixit et al., 2012). Numerous authors identify the appropriateness of utilizing EE as an indication for environmental impacts (Alcorn and Baird, 1996; Cole, 1999; Dixit et al., 2010; Aye et al., 2011; Crawford, 2011b; Cabeza et al., 2013). Researchers have also discussed the accuracies and inaccuracies of different methods and the appropriateness of EE as a measurement unit. Buchannan and Honey (1994), Treloar et al. (2001), Crawford and Treloar (2003), Dixit et al. (2010) and Langston and Langston (2013) are examples of these. Factors identified to influence the accuracy of EE analysis include the following: (a) the EE analysis process (input-output, process, statistical analysis and hybrid options), (b) system boundaries, (c) geographic locations, (d) age of data source, (e) source of data, (f) completeness of data and (g) feedstock energy consideration (Dixit et al., 2010; Dixit et al., 2012). Given the identification of such factors influencing EE analysis, variability in structural estimations of EE could be expected; however, no code or legislative requirements detail information to identify the most appropriate selection.

\section{A SYSTEMATIC RESEARCH APPROACH}

To evaluate appropriately the research knowledge in this area, a systematic approach was conducted to collect a suitable indication of the publications in this field. Published peer-reviewed literature on the EE and life cycle costs of structures were obtained by searching electronic databases of appropriate journals. Given the global significance of SD, a number of well-known reliable scientific reports from global publications discussed were also included. This study only relied on peer-reviewed articles for the purposes of comparative analysis. Previous literature reviews (Ramesh et al., 2010; Sharma et al., 2011; Cabeza et al., 2013) were also included only where peer-reviewed sources had been included. From the original publications through which the data was collected and presented (Tables 1-3), only T1 - T3 studies where direct unit conversions and calculations could result in comparable outcomes were utilized. Where assumptions were required to calculate comparable results, the study was excluded.

To determine the life cycle energy contributions presented, clear distinction between life cycle phases was required in the original work. Where maintenance was further separated as its own life cycle stage, the contribution of that stage has been omitted given the variability of reasons for, and calculation of, this maintenance component between studies. As a result, some of the studies investigated do not make up $100 \%$ of the total life cycle energy contribution (Table 1).

For calculation of the environmental impacts in terms of $\mathrm{EE}$ and $\mathrm{CO}_{2}$ equivalent costs per unit area of building space, studies where direct calculation and unit conversion were included. No assumptions were made in the determination of these values. In studies where there were multiple estimations for the same structural material based on investigations into multiple samples, if the coefficient of variance was less than 0.05 , then the average was presented. The countries were summarized for the location of the focus building, to consider the influence of climate on energy performance.

A total of 211 peer-reviewed papers were located and included as part of this review study with those satisfying the criteria discussed summarized and presented. A database of the suitable results was prepared to assess the outcomes obtained. Given the variability in the outcomes reported as well as the differences in calculation methods, it was not possible to present any meaningful statistical analysis of the results. This was a result of the following variables: system boundaries, building/material life spans and life cycle analysis (LCA) techniques.

\section{LIFE CYCLE ASSESSMENT: THE CONTRIBUTION OF TWO IMPORTANT STAGES}

Buildings are appropriately assessed within the life cycle context (Cole and Kernan, 1996; CoA, 2006; Crawford, 2011a; Baek et al., 2013). Due largely to the published dominance of the OE phase of a buildings life cycle when compared with $\mathrm{EE}$, the focus of the industry has been mainly on this phase. Given the variability in published values for the contribution of these phases, it is often difficult for a structural design team to assess environmental performance or place meaningful weighting to any structural life cycle aspect. Appropriately weighting a structure's life cycle energy contribution and related environmental performance remains subjective. Although it is noted that there are a number 


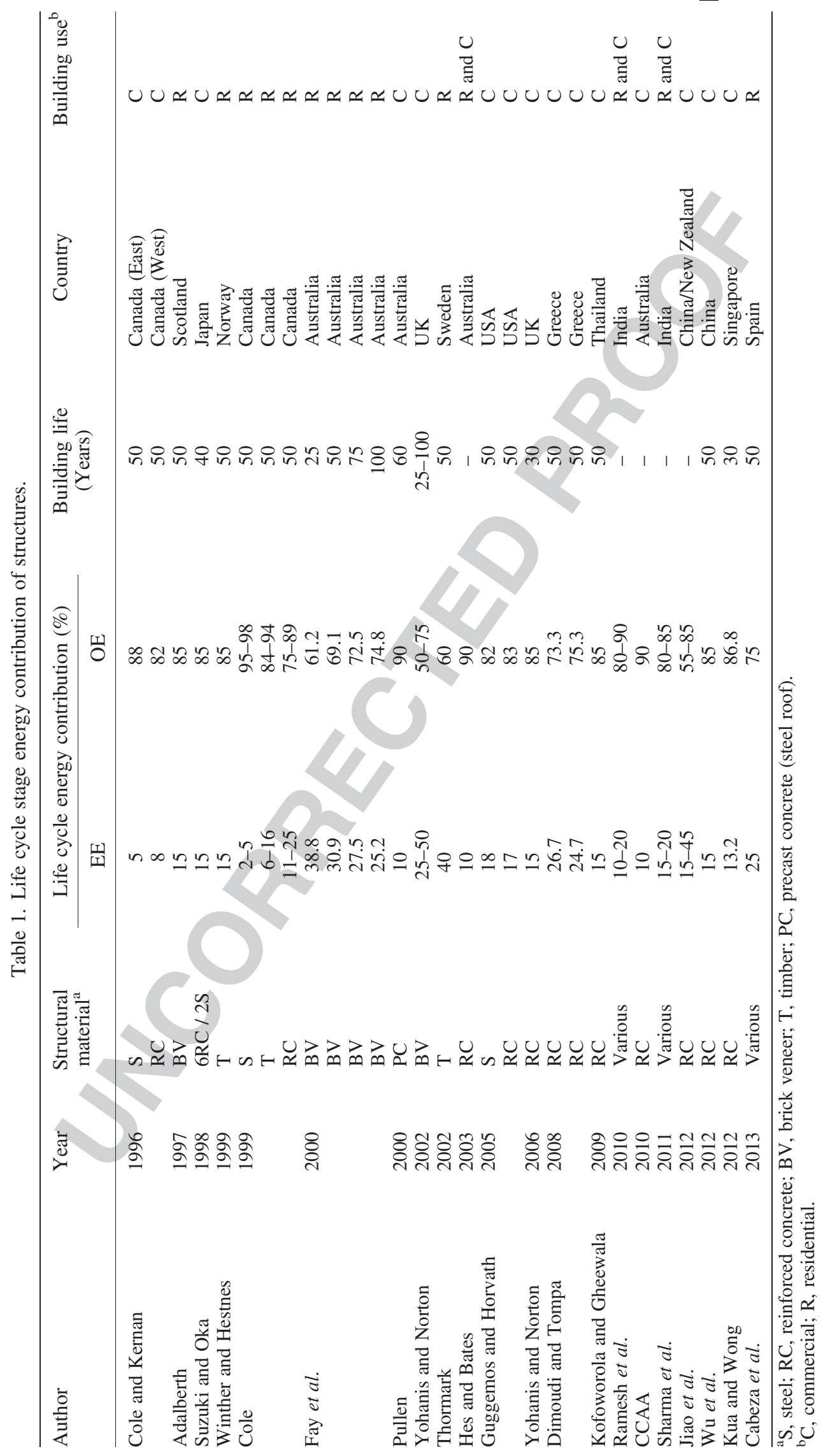


Table 2. Embodied energy and $\mathrm{CO}_{2}$ emissions attributed to structures.

\begin{tabular}{|c|c|c|c|c|c|c|c|c|}
\hline \multirow[t]{2}{*}{ Author } & \multirow[t]{2}{*}{ Year } & \multicolumn{3}{|c|}{$\begin{array}{l}\text { EE of building space by } \\
\text { structural material }\left(\mathrm{GJ} / \mathrm{m}^{2}\right)\end{array}$} & \multicolumn{3}{|c|}{$\begin{array}{l}\mathrm{CO}_{2} \text { of building space by } \\
\text { structural material }\left(\mathrm{kg} / \mathrm{m}^{2}\right)\end{array}$} & \multirow[t]{2}{*}{$\begin{array}{l}\text { Building } \\
\text { type }^{\mathrm{a}}\end{array}$} \\
\hline & & Steel & Concrete & Brick veneer & Timber & Steel & Concrete & \\
\hline Stein et al. & 1976 & 18.6 & 18.6 & - & - & - & - & $\mathrm{C}$ \\
\hline Honey and Buchanan & 1992 & - & $3.4-6.5$ & - & - & - & 5 & $\mathrm{C}$ \\
\hline Oka et al. & 1993 & - & $8-12$ & - & - & - & & $\mathrm{C}$ \\
\hline Buchanan and Honey & 1994 & - & 8.23 & - & - & - & & $\mathrm{C}$ \\
\hline Tucker and Treloar & 1994 & - & 8.2 & - & - & - & & $\mathrm{C}$ \\
\hline Suzuki et al. & 1995 & 0.005 & $8-10$ & - & 250 & 400 & 850 & $\mathrm{R}$ \\
\hline Debnath et al. & 1995 & - & $3.1-5$ & - & - & - & - & $\mathrm{R}$ \\
\hline Cole and Kernan & 1996 & 5 & 4.7 & - & - & - & - & $\mathrm{C}$ \\
\hline Yohanis and Norton & 1998 & 6.6 & 5.6 & - & - & - & - & $\mathrm{C}$ \\
\hline Suzuki and Oka & 1998 & - & 8.95 & - & - & - & 790 & $\mathrm{C}$ \\
\hline Cole & 1999 & 0.005 & 0.017 & - & $0.8-2$ & $0.4-1$ & $2.4-3$ & $\mathrm{R}$ \\
\hline Fay et al. & 2000 & - & - & 14.1 & - & - & - & $\mathrm{R}$ \\
\hline Treloar et al. & 2000 & - & - & 11.7 & - & - & - & $\mathrm{R}$ \\
\hline Pullen & 2000 & - & 11.0 & - & - & - & - & $\mathrm{C}$ \\
\hline Yohanis and Norton & 2002 & 9.5 & - & - & - & - & - & $\mathrm{C}$ \\
\hline Venkatarama and Jagadish & 2003 & - & 4.21 & - & - & - & - & $\mathrm{R}$ \\
\hline Guggemos and Horvath & 2005 & 9.5 & 8.3 & - & - & 620 & 550 & $\mathrm{C}$ \\
\hline Yohanis and Norton & 2006 & - & 8.9 & - & - & - & 790 & $\mathrm{C}$ \\
\hline Citherlet and Defaux & 2007 & - & - & 2.6 & - & - & - & $\mathrm{R}$ \\
\hline Shukla et al. & 2008 & - & - & & - & - & - & - \\
\hline Dimoudi and Tompa & 2008 & - & $1.93-3.27$ & & - & - & 199.8-298.4 & $\mathrm{C}$ \\
\hline Kofoworola and Gheewala & 2009 & - & 6.8 & - & - & - & - & $\mathrm{C}$ \\
\hline Fuller and Crawford & 2011 & - & 2.22 & - & - & - & - & $\mathrm{R}$ \\
\hline Wu et al. & 2012 & - & 9.4 & - & - & - & 803 & $\mathrm{C}$ \\
\hline Kua and Wong & 2012 & - & 5.96 & - & - & - & 823 & $\mathrm{C}$ \\
\hline
\end{tabular}

${ }^{\mathrm{a}} \mathrm{C}$, commercial; R, residential.

Table 3. Embodied energy estimations of structural materials.

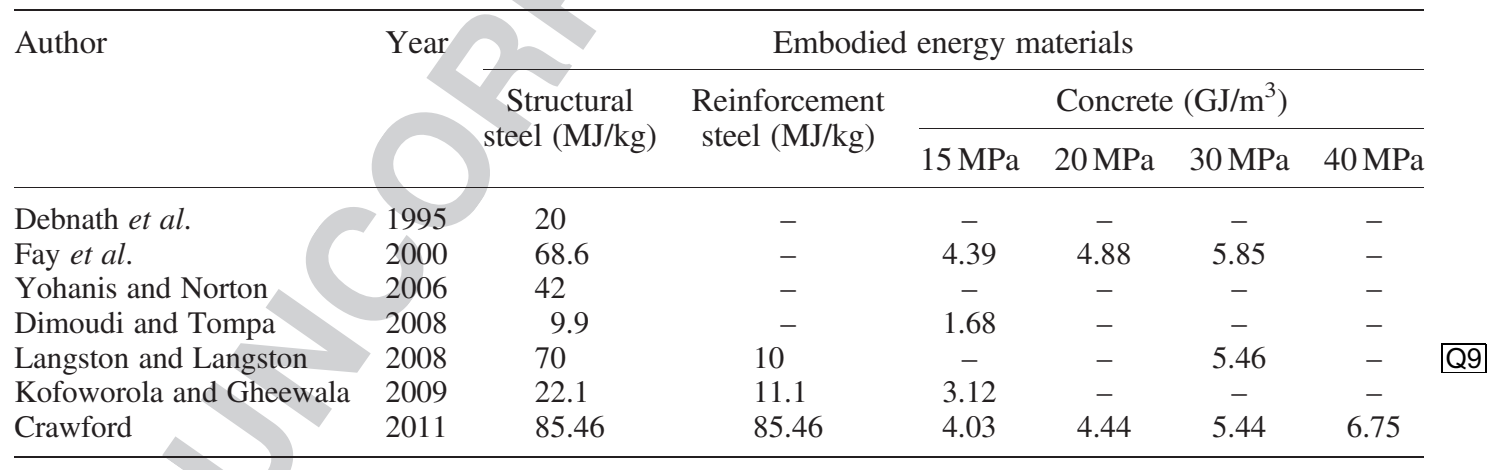

of processors contributing to the variability in the published values, it is for this very reason that confusion remains.

Several published studies question the accuracy of previous studies based usually on system boundary inconsistencies and the methodology used to calculate the OE and/or EE (Fay et al., 2000; Junnila et al., 2006; Dimoudi and Tompa, 2008; Crawford, 2011a; Stephan et al., 2011; Dixit et al., 2012; Dixit et al., 2013; Omar et al., 2013). After a systematic assessment of the published values detailing the contribution of each of these life cycle stages, the following summary was presented (Table 1).

Results indicate that as little as $2 \%$ of a structures overall life cycle energy contribution for a lightweight steel residential building (Cole, 1999) can come from the EE phase, whereas as much as $40 \%$ for a low-energy building in Sweden can be attributable to the same life cycle phase (Thormark, 2002). 
On the basis of an assessment of the published literature, it is evident that the variability resulting from the calculation procedure can produce different outcomes. Building life, system boundary, butilding use

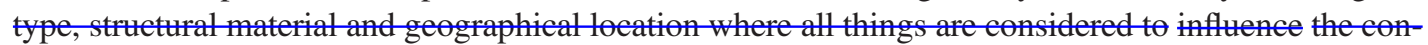
tibution as a result of EE and OE. This variability was seen between studies. The ef- Q10 Q11 fect of varying building life was shown in some cases to heavily reduce the energy contribution of the EE aspect.

\section{EMBODIED ENERGY AND ITS VARIABILITY}

Energy is an essential component in the building industry. The construction, operation and maintenance of buildings are commonly estimated to account for approximately $40 \%-50 \%$ of all energy usage (Hasegawa, 2003; Smith, 2005; Asif et al., 2007; Citherlet and Defaux, 2007; Wood, 2007; Dimoudi and Tompa, 2008; Stephan et al., 2011; Dixit et al., 2012; Langston and Langston, 2013; Baek et al., 2013). EE is defined broadly as the energy consumed in all activities to support a process. Numerous previous studies have refined this definition often depending on a specific end-user application. It is well published and understood that truncation errors associated with system boundaries are a substantial causal issue for inaccurate energy assessment in a structures LCA. There are four different EE analysis methods described in the literature with shortfalls of each regularly highlighted. These four methods include the following: process analysis, statistical analysis, input-output analysis and hybrid analysis. No method is perfect with inaccuracies estimated at approximately 20\% (Treloar, 1997; Langston and Langston, 2013).

Previous studies have analysed the EE of structures exhibiting results displaying variability as a consequence of these factors. Issues in relation to the variability exhibited make meaningful comparison impossible. Inaccurate, incomplete results from studies whose assumptions and processors exhibit the outcomes presented make decision making difficult to undertake (Dixit et al., 2010; Dixit et al., 2012). Policy makers, structural designers, architects, clients and relevant stakeholders require reliable rigorous datasets to ensure progress. At present, determining the $\mathrm{EE}$ of a building material is subjective due to the lack of global or national standardized methods with this further influencing the variability observed (Goggins et al., 2010).

The summary presented in Table 1 included the energy associated with both the EE and OE requirements. OE requirements are far more conventional with less scope for the system incompleteness and inconsistencies present in the EE estimations. Table 2 highlights the variability discussed by presenting both the EE of the main structural materials used in the construction industry as well as the associated carbon footprint standardized by square meter of building space. These values presented have been obtained from studies incorporating the estimations based on whole structural systems.

Given the variability observed, it is evident that the incompleteness and inconsistencies present could result in disorderly outcomes. There is an urgent requirement for the building industry to calculate the expected energy performance in terms of $\mathrm{EE}$ and $\mathrm{OE}$ as well as $\mathrm{CO}_{2}$ equivalent to enable more meaningful assessment across the relevant stakeholders. For concrete structures, estimations varied from $0.017 \mathrm{GJ} / \mathrm{m}^{2}$ to $18.6 \mathrm{GJ} / \mathrm{m}^{2}$ depending on which of the EE analysis methods, material datasets and calculation procedures were used (Table 2). Similarly, for structural steel buildings, values from $0.005 \mathrm{GJ} / \mathrm{m}^{2}$ to $18.6 \mathrm{GJ} / \mathrm{m}^{2}$ were reported.

The factors influencing the variability in $\mathrm{EE}$ assessments previously discussed and presented by Dixit et al. (2010) establishes that these outcomes could be expected. Despite this, meaningful guidance to practicing structural engineers is lacking with no accepted standardized process or assessment methodology being established, either compulsorily or optionally. From a practical structural design perspective, selection of any of the data presented (Table 2) could be appropriately justified under certain design circumstances when assessing environmental performance. This would result in wide ranging estimations of environmental performance, should the extremities of this data be utilized. On the basis of the factors presented by Dixit et al. (2010), with extensive research, structural engineers could appropriately narrow down the selection of what are considered more accurate EE options, mitigating known EE inaccuracies. The instigation of a more accurate protocol is essential to streamlining and simplifying environmental assessment for these professionals. 
Due to the reliance of the values reported in Table 2 on the material database used, a cross-section of the published values have been summarized for the main structural materials used in these buildings. It is evident that due to the results in Table 2 being a function of those, the inconsistencies present across the entire building industry are the result of an incomplete environmental performance building assessment system. Table 3 presents published EE estimations per unit of material. As observed for both the comparisons of life cycle phase energy use and EE estimations (Table 1 and 2), the same incompleteness and inconsistencies are seen (Table 3).

\section{CASE STUDY: A TYPICAL SOUTH-EAST QUEENSLAND CONCRETE OFFICE BUILDING}

The requirement for accurate determination of environmental performance in a structural system is unquestioned, however a calculation mechanism remains elusive (Paya-Zaforteza et al., 2009; Dixit et al., 2010; Crawford, 2011a; Dixit et al., 2012). To investigate the viability of savings achievable through the selection of alternate design approaches and construction methodologies, a detailed comparative assessment was performed for a typical office structure in the South-East Queensland region of Australia. This investigation was to assess the relative environmental performance of alternate slab construction techniques and determine variability in this performance for systems meeting the design criteria. To achieve this, a multi-stage research methodology was formulated. This methodology was categorized into two major components, structural design and environmental analysis. The structural design involved several distinct components including the following: (a) Design definition: including the formulation for the design of the specific building to be analysed along with the identification of assumptions necessary to undertake the analysis. (b) Manual calculations in accordance with AS3600-2009 to provide a detailed design of the structural element varied (slab) that was used for inputs into the two-dimensional computer analysis program, RAPT. (c) The structural designs were finalized using the results obtained from the computer analysis. These were verified using comparison with hand calculations to ensure accuracy and suitability of the design. (d) The structural requirements for each element were subsequently detailed allowing a bill of quantities (BOQ) to be generated and an environmental performance assessment undertaken. The research methodology has been summarized in Figure 1.

The typical office structure investigated comprised of a 10-storey building. This was designed and analysed using both post-tensioned and conventional reinforced concrete slabs (40-MPa concrete). The slab span was varied to evaluate four column centre spacings of $6.67 \mathrm{~m}, 8 \mathrm{~m}, 10 \mathrm{~m}$ and $13.33 \mathrm{~m}$. This layout resulted in the analysis of the building containing three-six clear spans for the total exterior fixed building footprint of $40.5 \mathrm{~m} \times 40.5 \mathrm{~m}$. Typical flat plate slab construction system was used, supported on a square grid of $500 \times 500 \mathrm{~mm}^{2}$ columns with 3.5 -m floor-to-floor heights. Different slabs were designed due to varying loading requirements for the roof slabs in each structure.

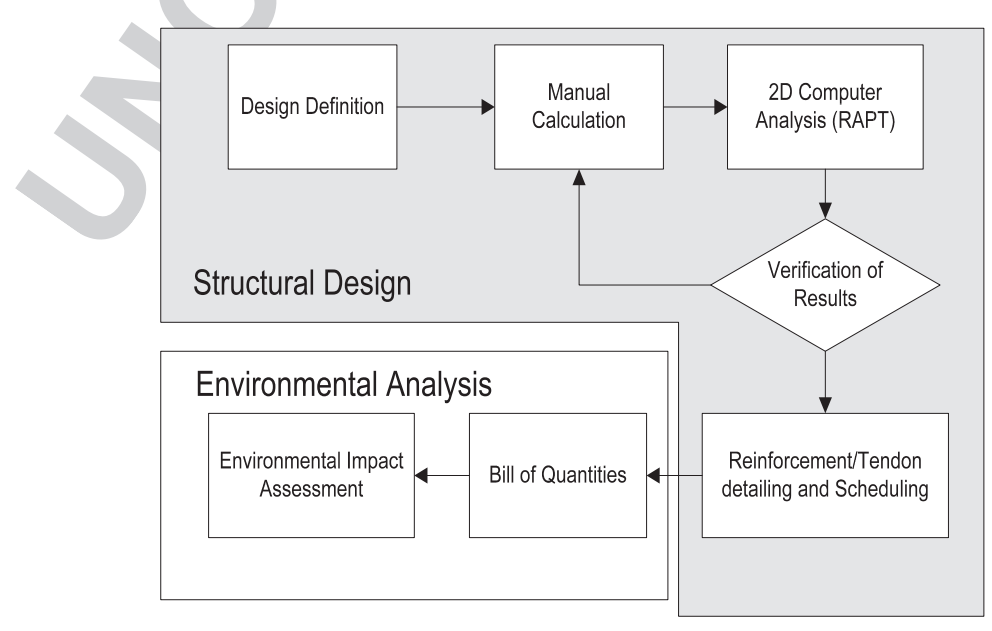

Figure 1. Methodology for structural design and environmental analysis. 
A simplified single level plan for the 8-m-span layouts investigated for the structure, including plan dimensions, has been included for reference (Figure 2). The external building dimensions were fixed to F2 simulate actual building constraints (land size), and the internal spans between columns were varied to assess the influence this has on the outcomes of the different slab systems investigated.

\subsection{Strength and serviceability design methodology}

AS3600-2009 dictates that concrete structures shall be designed for both ultimate strength and serviceability limit state requirements in accordance with loading conditions specified in AS1170. All structures presented have been designed in accordance with these requirements. In addition, software-modelling verification was conducted. Determination of the required slab thickness was conducted as an iterative process that continued through the analysis. This was affected by many factors and design parameters. The most efficient slabs display a minimum required thickness to control deflection and punching shear while maintaining acceptable reinforcement requirements. A minimum control over long-term deflection of $\frac{\Delta}{L_{\mathrm{ef}}} \leq \frac{1}{250}$ was adopted for an office slab in compliance with Clause 2.3.2 in AS3600-2009 (SAA, 2010). In addition, a minimum control over incremental deflection of $\frac{\Delta}{L_{\mathrm{ef}}} \leq \frac{1}{500}$ for all floor slabs was adopted. This deflection requirement is critical in members supporting masonry partitions and brittle finishes, which are present in most multi-storey office structures of this height. Application of these minimum deflection limits using the deemed to comply span-to-depth ratio for reinforced concrete slabs, as detailed in Clause 9.3.4 (SAA, 2010), provided an initial indication of the required thickness for the reinforced concrete slabs. The standard provides no simplified methods to determine the thickness of a post-tensioned slab. In large spans, it is more effective to use a span-depth ratio to determine the slab thickness. While various span-depth ratios are suggested in a number of published literature, those quoted by the Cement and Concrete Association of Australia Guide to Long Span Concrete Floors (CCAA, 2003) were used. When calculating the deflection, the elastic short-term deflection as well as time-dependent deflections caused by sustained load, or creep, and drying shrinkage were all taken into account as these heavily influence the magnitude of deflection experienced within a slab. To meet all relevant standards including structural adequacy, durability, fire resistance and acoustic performance, a minimum slab depth of $200 \mathrm{~mm}$ was required along with a minimum clear cover of $29 \mathrm{~mm}$ to provide a minimum axis depth of $35 \mathrm{~mm}$ when N12 bars are utilized. For the posttensioned slabs, the code specifies an additional 10-mm concrete cover to tendons than that required for typical reinforcement. This requirement was accounted for by allowing $30-\mathrm{mm}$ clear cover to the duct. The additional cover is available within the void; therefore, this design meets all relevant requirements.

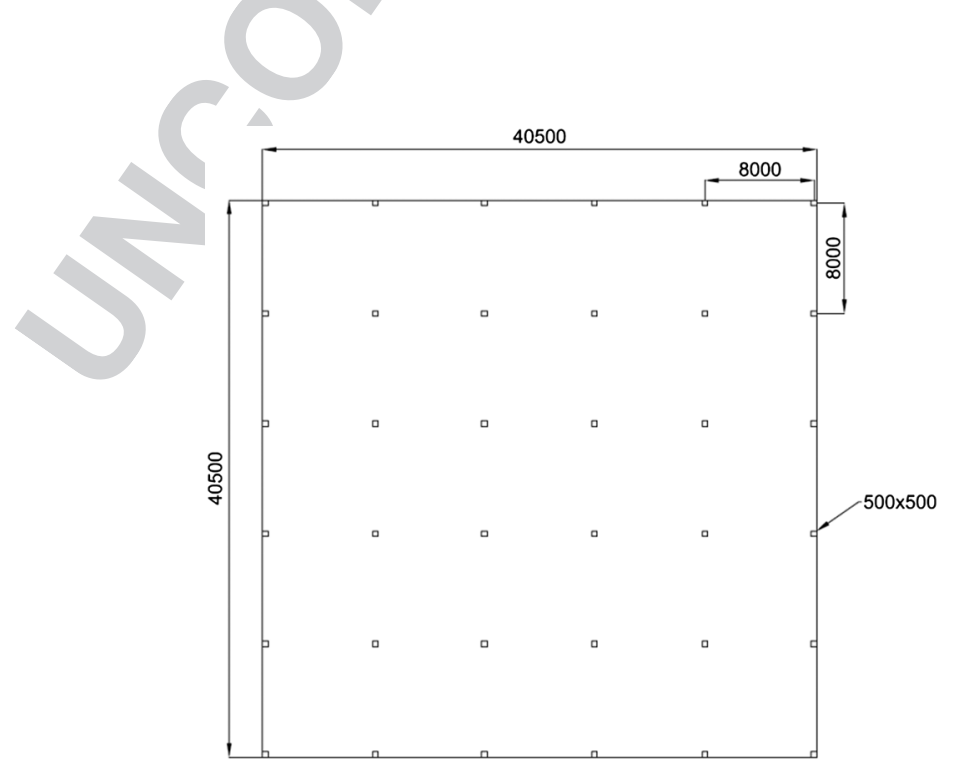

Figure 2. Simplified building plan example, Stage 1 (8-m span layout). 


\subsection{Environmental analysis}

The Environmental Impact Assessment was undertaken using data obtained from the literature review (Tables 1-3), as well as previous publications from the authors (Miller et al., 2013). Despite the variability in environmental impact measures (Table 2), some estimations are more comprehensive. Numerous studies have detailed the inefficiencies present in different life cycle assessment methodologies leading to this (Dixit et al., 2010; Crawford, 2011a; Dixit et al., 2012; Omar et al., 2013). As a result, the EE values published by Aye et al. (2011) and Crawford (2011a) were determined to be most suitable for this assessment and were used for the environmental analysis. Selection was based on the analysis method used (input-output-based hybrid method) being the most comprehensive, complete analysis approach currently available (Dixit et al., 2010; Aye et al., 2011; Dixit et al., 2012). Selection was also based on geographical vicinity to the region, another key issue to EE inaccuracies, identified by Dixit et al. (2010).

Although it is noted that high-strength steel tendon fibres undergo different manufacturing procedures, there is significant limitations in current literature identifying suitably accurate values of EE. There was no value specified for EE of steel tendons in the study undertaken by Crawford (Crawford, 2011a). To adopt an appropriate value, a conservative approach was taken in consultation with manufactures and the published literature on other steel EE values. The value adopted here was estimated to be 50\% greater than the detailed estimation of steel reinforcement calculated by Crawford (2011a). These values have been summarized in Table 4 .

\subsection{Analysis results}

Material requirements from the BOQ were applied factors to quantify the environmental impacts of materials in each floor and roof slab for both construction types. Slab results were combined together with concrete columns to form results for whole building structural material requirements. These material requirements, as determined from the BOQ for alternate slab construction techniques, are presented (Figures 3 and 4). Results indicate a significant reduction in material requirements being F3 F4 achieved through the implementation of post-tensioned construction methods.

Table 4. Embodied energy values utilised for environmental impact assessment.

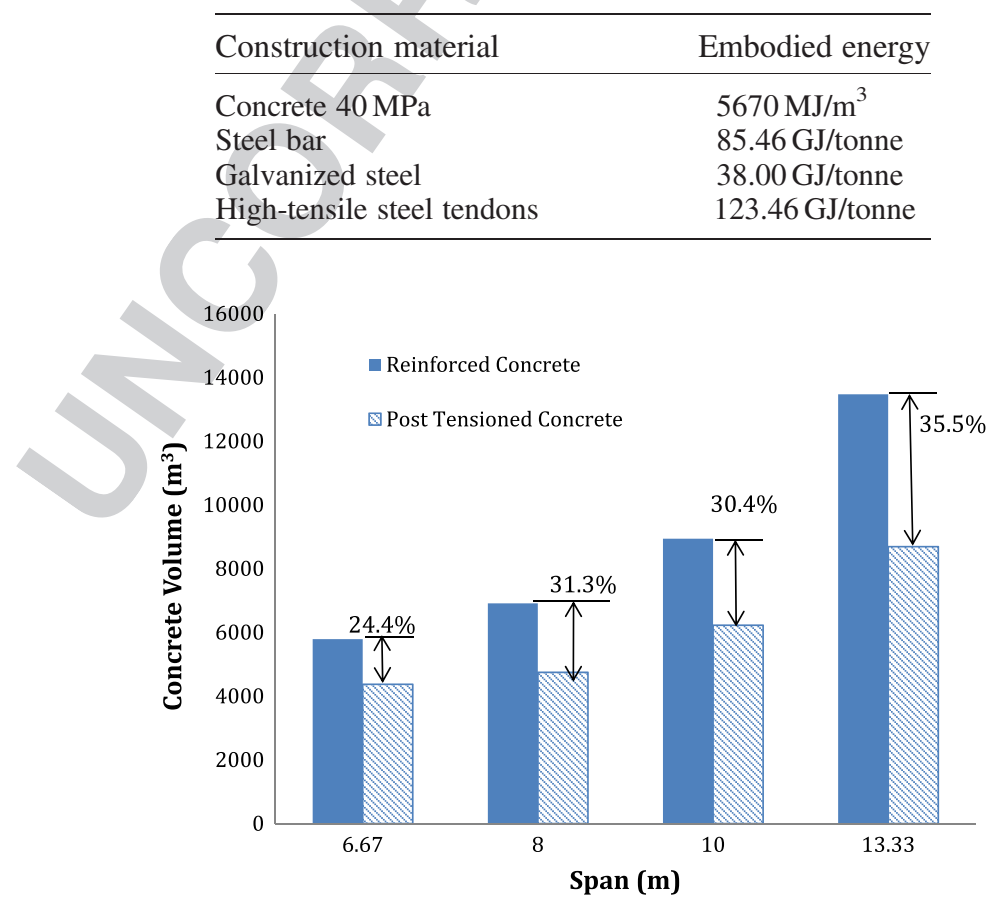

Figure 3. Concrete volumes of reinforced and post-tensioned concrete buildings. 


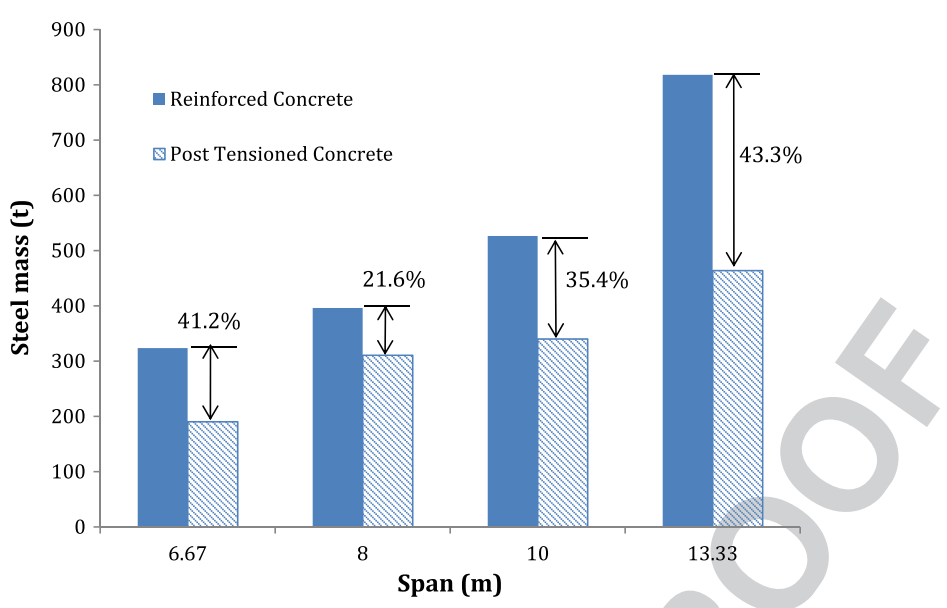

Figure 4. Steel mass of reinforced and post-tensioned concrete buildings.

Using a typical concrete strength of $40 \mathrm{MPa}$, it was observed that reductions in concrete volume, through the use of post-tensioning, increase with increasing span length. These ranged from $24.4 \%$ for a $6.67-\mathrm{m}$ span and increasing up to $35.5 \%$ for a $13.33-\mathrm{m}$ span. This indicates that the use of post-tensioning in large spans is more efficient in terms of material reductions. The analysis also indicates that the use of post-tensioning results in concrete material efficiency improvements in all cases.

Similar reductions in steel material requirements are evident with increased span as shown in Figure 4. The $6.67-\mathrm{m}$ span was observed to achieve the largest material reduction when the post-tensioned construction technique was used. Generally, it shows that the span length plays a large role in this, being able to reduce the steel mass by between $21.6 \%$ and $43.3 \%$ when span length increases from $8 \mathrm{~m}$ to $13.33 \mathrm{~m}$. This indicates the usage of pos- tensioning in structures with greater spans being more efficient at minimizing material requirements for that particular structure. In the case of the $6.67-\mathrm{m}$ span, it was evident that a larger reduction in steel mass was obtainable due to design reasons. This was the only span where tensile stresses were below $0.25 \sqrt{f_{c}^{\prime}}$ resulting in an economical design for the post-tensioned slabs. Crack control in the form of unstressed bars at 300-mm spacing were not required for this variation, resulting in a lower mass of steel being required. Further, temperature and shrinkage requirements were easily satiated as no additional reinforcement was suggested to satisfy the relevant design codes.

Values for EE were determined for comparison of the environmental performance of the two structures when the alternate slab construction methods were employed. The calculated EE resulting from the concrete volume and steel mass requirements of individual floor and roof slabs are displayed in Figures 5-9. Results indicate similar extensive savings are experienced in the EE of both the floor and roof $\mathbf{F 5}-\mathbf{F 9}$

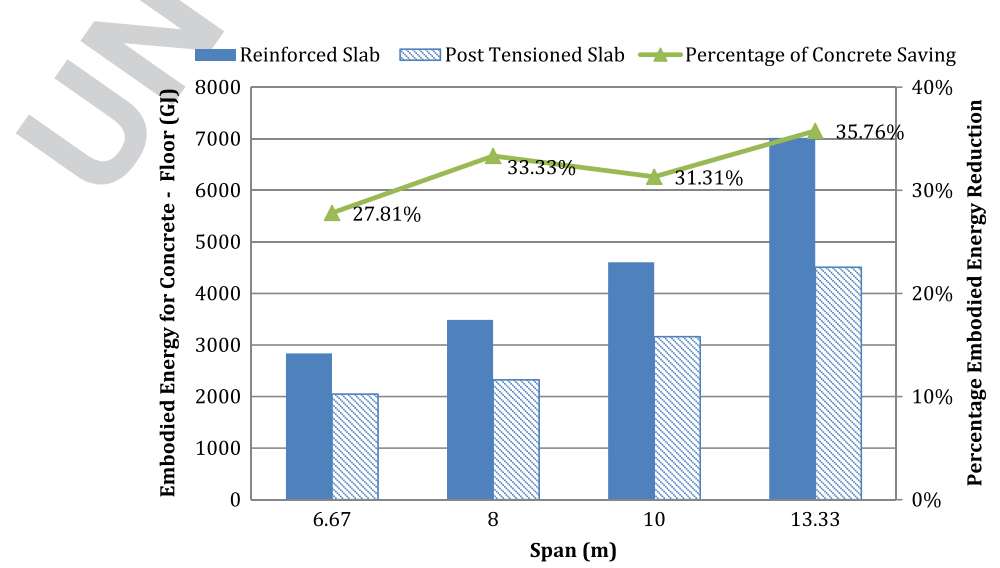

Figure 5. Embodied energy of concrete for floor slab and comparative reductions. 


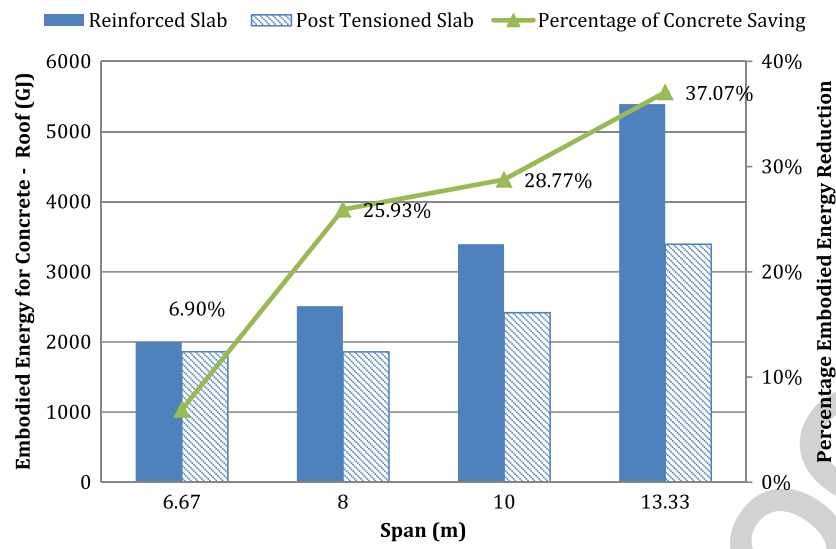

Figure 6. Embodied energy of concrete for roof slab and comparative reduction.

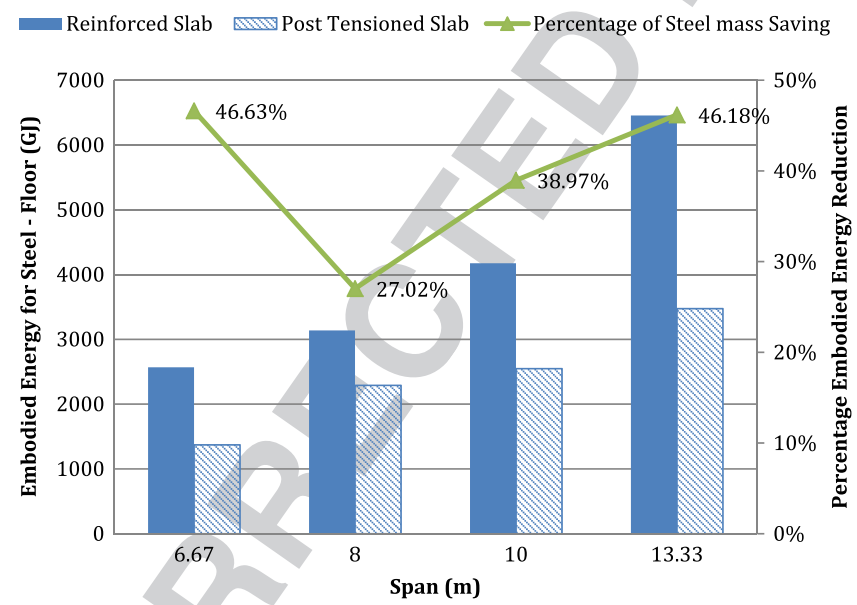

Figure 7. Embodied energy value of steel for floor slab and comparative reduction.

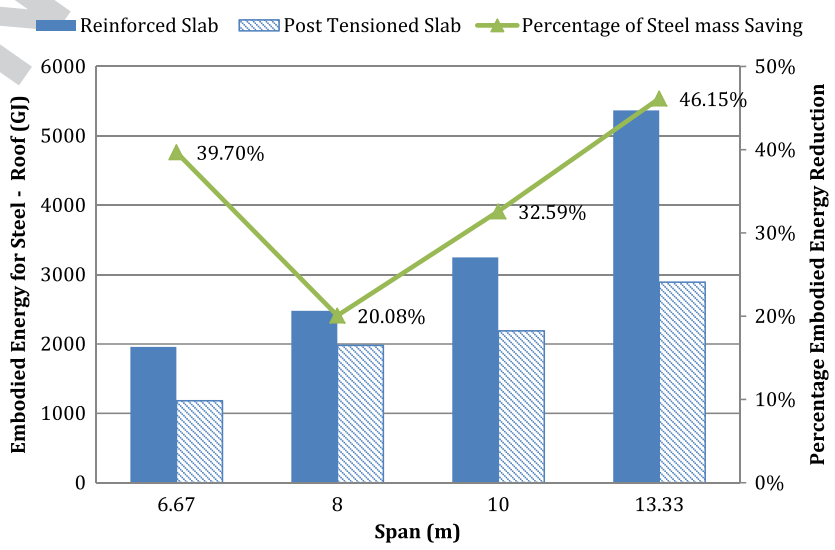

Figure 8. Embodied energy value of steel for roof slab and comparative reduction. 


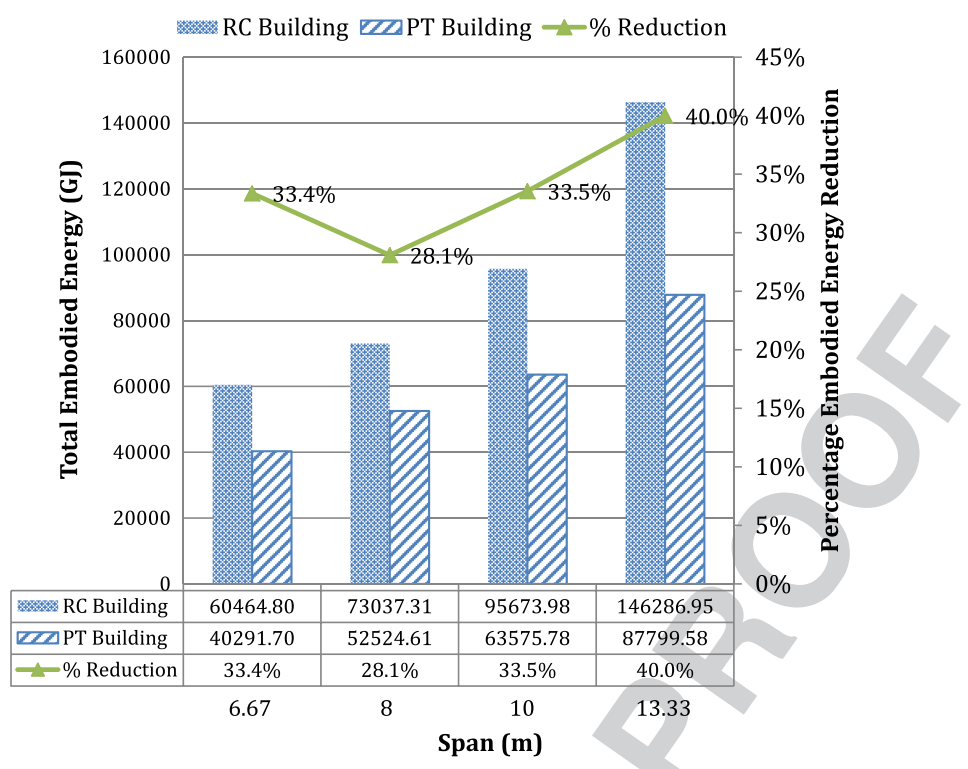

Figure 9. Total embodied energy of the structural elements for reinforced concrete (RC) and posttensioned (PT) buildings.

slabs. Results are presented for each of the four spans investigated of both conventionally reinforced and post-tensioned floor and roof slabs.

The total environmental impacts for each slab are indicated as individual contributions of the concrete and steel components. Comparison of the unit environmental impacts for steel and concrete by mass, indicate the EE of steel is at least 25 times that of concrete.

Total EE contribution for concrete of both floor and roof slabs, respectively, were studied. EE reductions due to concretes contribution in the floor slab are evident for all spans investigated, with results indicating a $27.81 \%-35.76 \%$ reduction in EE (Figure 5). These reductions increased as span length increased. Similarly, reductions in EE contribution for concrete of roof slabs are observed for all spans investigated. These varied between $6.90 \%$ and $37.07 \%$ (Figure 5). The lower bound was dictated due to minimum slab depth requirements governing further available reductions.

Total EE contribution for Steel of both floor and roof slabs, respectively, are also presented. EE reductions due to steels contribution in the floor slab are evident for all spans investigated, with results indicating a $27.02 \%-46.63 \%$ reduction in EE (Figure 6). These reductions generally increase as span length increased for above 8-m spans. Similarly, reductions in EE contribution for steel of roof slabs are observed for all spans investigated. These varied between $20.08 \%$ and $46.15 \%$ (Figure 7). Reductions observed in steel contribution for the $6.67-\mathrm{m}$ spans were larger due to a design parameter. As presented above, tensile stresses were below $0.25 \sqrt{f_{\mathrm{c}}^{\prime}}$ resulting in an economical design for the post-tensioned slabs. Crack control in the form of unstressed bars at 300-mm spacing was not required.

The total EE of the office structure investigated were calculated (Figure 8). These indicate potential variations in EE of a structural system through alternate slab design selection. Overall improvements as a result of the selection of alternate slab construction techniques are evident. In total, EE reductions were observed for all structures incorporating post-tensioned slab construction. These EE reductions ranged from $28.1 \%$ to $40 \%$ when compared with conventionally reinforced concrete construction.

When considering all structural systems investigated, estimations of total EE ranged from $40292 \mathrm{GJ}$ to $146287 \mathrm{GJ}$ ( $\approx 3.6$ times). Whereas span length and slab type varied, the completed structure remained identical. When considering this outcome, the requirement for a quantification mechanism detailing the environmental performance of a structure is essential. Incentives to encourage practitioners to achieve the most efficient outcome are also required.

The disproportionate contribution of $\mathrm{EE}$ when compared with material mass was significant, highlighting the importance of reducing steel requirements in minimizing EE. In conventionally 
reinforced structures assessed, despite steel only contributing between $2 \%$ and $3 \%$ of total material mass, the EE for steel accounted for between $45.73 \%$ and $47.79 \%$. In post-tensioned structures, the contribution of steel accounted for between $1.8 \%$ and $2.7 \%$ of mass, whereas it accounted for between $38.48 \%$ and $48.77 \%$ of EE.

\section{DISCUSSION AND CONCLUSION}

The reported values highlight the variability present in environmental performance measures across the building industry. On the basis of the parameters used to determine the environmental performance of any given structure, variability in the outcomes are extensive. While there exists an inconsistency in the literature regarding the life cycle context, system and methodology with which to appropriately assess the environmental performance of a structure, the requirement for its quantification is extensively supported (Paya-Zaforteza et al., 2009; Dixit et al., 2010; Crawford, 2011a; Dixit et al., 2012). A standardized approach at rating structural systems and the associated EE and or environmental impacts is urgently required, comparable with that proposed by Dixit et al. (2012). The factor that will detail its effectiveness is adoption. Table 1 highlights the perplexity mentioned (Adalberth, 1997a), with design teams frequently overruled by other consultants in the strive to achieve 'sustainable buildings'. A concentrated cooperative legislative approach may be required if voluntary adoption does not improve. While there are a multitude of studies evaluating the life cycle contribution and EE of materials, it is generally accepted and presented herein that there outcomes are inconsistent. The entirety of the literature and the existing green building rating systems support the improvements in OE efficiencies as being the method by which to achieve sustainable buildings.

Thormark (2002) reported the largest contribution from the construction phase in terms of EE investment at $40 \%$ with the majority being a far less significant contribution. Given this outcome, the focus of existing green building ratings systems on the OE requirements appears appropriate. While the consensus in these studies in undoubtedly the majority of the life cycle energy use of buildings being attributed to these $\mathrm{OE}$ requirements, technology and necessity are progressing the development and use of renewable resources. In the studies reviewed, no life cycle energy requirements were said to include the consideration of the use of renewable energy sources. There is a focus by governments, industry and consumers to decrease reliance on energy generated by fossil fuels. As an example, the Australian Government has revised its target for the country to supply $20 \%$ of its energy needs from renewable resources by 2020 (Zahedi, 2010). As the percentage of energy produced from renewable resources increases, the OE-related impacts would decrease proportionally. While these still consume the same level of energy by definition, the environmental impacts are reduced or negated when compared with those of fossil fuel energy sources.

Of greater significance to the contribution of life cycle phases is the emergence of ZEBs. A number of studies are beginning to emerge in the development of these ZEB (Crawford, 2011b; Marszal and Heiselberg, 2011; Monahan and Powell, 2011; Zuo et al., 2012a). If achieved, the contribution of the OE phase would be removed entirely. The consequences of this leap forward for the building industry would be enormous in terms of the way in which environmental efficiency is achieved through the built environment. The focus of the design teams, building ratings systems, policy makers and stakeholders would need a monumental shift towards the factor that has been generally accepted as presently the least considered: EE consumption (Thormark, 2002; Yohanis and Norton, 2002; Yohanis and Norton, 2006; Stephan et al., 2011). If achieved, the major life cycle energy contribution will be EE. Consequently, any EE reductions will positively contribute to the environmental performance of the structure.

There is no generally accepted method available to accurately determine EE consistently resulting in variations being observed (Dixit et al., 2010). If developed, this would remove a major obstruction to the widespread production of environmentally efficient structures. Given the global extent of development-related impacts associated directly to the operation, maintenance and demolition of buildings (Hasegawa, 2003; Smith, 2005; Asif et al., 2007; Citherlet and Defaux, 2007; Wood, 2007; Dimoudi and Tompa, 2008; Stephan et al., 2011; Dixit et al., 2012; Langston and Langston, 2013; Baek et al., 2013), the development of such a system would provide substantial improvement in the 
contribution of the building industry to achieving the principles of SD. The economic and social benefits discussed (Lippiatt, 1999; EU, 2001; CCAA, 2010), and the variability in the environmental considerations of building presented indicate the need for the development of a meaningful quantifiable EE assessment methodology for the structural design of buildings. Such an approach would include the appropriate life cycle context focus as well as the EE methodological processes identified to most accurately calculate the EE present in a structural system the (input-output-based hybrid method) (Dixit et al., 2010; Aye et al., 2011; Dixit et al., 2012).

As a multitude of researchers grapple with the task of producing, implementing and adopting a national or international standardized system, there exists extensive scope for structural engineers to improve the way in which environmental performance is measured utilizing present knowledge and technology. By investigating the variability in environmental performance of two different commonly used slab construction techniques, results delivering equal building function were obtained with up to 3.6 times more EE, conditional upon design parameters. Whereas the accuracy of the quantified value of environmental performance is unknown, the relative environmental performance would remain.

The development of a standardized system is paramount for the environmental assessment of the structural design of structures. The variability presented and discussed results in inconsistencies and limited consideration by practising structural engineers. Such systems have been extensively discussed, for example that prosed by Dixit et al. (2012); however, to date, no mechanism has been introduced or is universally accepted.

\section{ACKNOWLEDGEMENTS}

Alliance Design Group (ADG) Consulting Engineers (www.adgce.com) has provided extensive support and resources to the development of this research topic. Through the past 5 years, ADG and its chairman Mr Tim Peters have supplied technical and practical support through research associates and projects. The authors would like to acknowledge Mr Peters and his team for their efforts. Specifically, the authors would also like to acknowledge Mr Mitchell Mulvey, for his efforts and input into the development of this research.

\section{REFERENCES}

Adalberth K. 1997a. Energy use during the life cycle of buildings: a method. Building and Environment 32: 317-320.

Adalberth K. 1997b. Energy use during the life cycles of single unit dwellings: examples. Building and Environment 32: 321-329.

Alcorn JA, Baird G. 1996. Use of hybrid energy analysis method for evaluating the embodied energy of building materials Wellington, New Zealand: Centre for Biulding Performance Research Victoria University.

Asif M, Muneer T, Kelley R. 2007. Life cycle assessment: a case study of a dwelling home in Scotland. Building and Environment 42: 1391-1394.

Australian Bureau of Statistics (Ab). 2010. 1370.0-Measures of Australia's Progress [Online]. Available: http://www.abs.gov. au/ausstats/abs@.nsf/Lookup/by Subject/1370.0 2010 Chapter Population projections (3.4).

Aye L, Ngo T, Crawford RH, Gammampila R, Mendis P. 2011. Life cycle greenhouse gas emissions and energy analysis of prefabricated reusable building modules. Energy and Buildings 47: 159-168.

Baek C, Park S-H, Suzuki M, Lee S-H. 2013. Life cycle carbon dioxide assessment tool for buildings in the schematic design phase. Energy and Buildings 61: 275-287.

Buchanan AH, Honey BG. 1994. Energy and carbon dioxide implications of building construction. Energy and Buildings 20: 205-217.

Cabeza LF, Barreneche C, Miro L, Morera JM, Bartoli E, Fernandez AI. 2013. Low carbon and low embodied energy materials in buildings. Renewable and Sustainable Energy Reviews 23: 536-542.

Cement C, Aggregates Australia, (Gat). 2010. Sustainable Concrete Buildings. Cement, Concrete \& Aggregates Australia: Sydney.

Cement and Concrete Association of Australia (Eeat). 2003. Guide to Long-span Concrete Floors. TechMedia Publishing Pty Ltd.

Chong WK, Kumar S, Haas CT, Beheiry SMA, Coplen L, Oey M. 2009. Understanding and interpreting baseline perceptions of sustainability in construction among civil engineers in the United States. Journal of Management in Engineering 25: 143-154.

Citherlet S, Defaux T. 2007. Energy and environmental comparison of three variants of a family house during its whole life span. Building and Environment 42: 591-598.

Cole RJ. 1999. Energy and greenhouse gas emissions associated with the construction of alternative structural systems. Building and Environment 34: 335-348.

Cole RJ, Kernan PC. 1996. Life-cycle energy use in office buildings. Building and Environment 31: 307-317.

Commonwealth of Australia, (CoA). 2006. Scoping Study to Investigate Measures for Improving the Environmental Sustainability of Building Materials. Canberra. 
Crawford RH. 2011a. Life Cycle Assessment in the Built Environment. Taylor and Francis: London.

Crawford RH. 2011b. Towards a comprehensive approach to zero-emissions housing. Architectural Science Review 54: $277-284$.

Crawford RH, Treloar GJ. Validation of the use of australian input-output data for building embodied energy simulation. Eighth International IBPSA Conference, 2003 Eindhoven, Netherlands, 11th-14th August, 2003; 235-242.

Debnath A, Singh SV, Singh YP. 1995. Comparative assessment of energy requirements for different types of residential buildings in India. Energy and Buildings 23: 141-146.

Dimoudi A, Tompa C. 2008. Energy and environmental indicators related to construction of office buildings. Resources, Conservation and Recycling 53: 86-95.

Dixit MK, Culp CH, Fernandez-Solis JL. 2013. System boundary for embodied energy in buildings: a conceptual model for definition. Renewable and Sustainable Energy Reviews 21: 153-164.

Dixit MK, Fernández-Solís JL, Lavy S, Culp CH. 2010. Identification of parameters for embodied energy measurement: a literature review. Energy and Buildings 42: 1238-1247.

Dixit MK, Fernández-Solís JL, Lavy S, Culp CH. 2012. Need for an embodied energy measurement protocol for buildings: a review paper. Renewable and Sustainable Energy Reviews 16: 3730-3743.

Engineers Australia (Ea). 2003. Policy statement—sustainable environmental practice. In: Engineers Australia National Council (ed.). Engineers Australia: Sydney.

European Union (Et). 2001. An agenda for sustainable construction in Europe. Brussels.

Fay R, Treloar G, Iyer-Raniga U. 2000. Life-cycle energy analysis of buildings: a case study. Building Research \& Information 28: $31-41$.

Fuller RJ, Crawford RH. 2011. Impact of past and future residential housing development patterns on energy demand and related emissions. Journal of Housing and the Built Environment 26: 165-183.

Goggins J, Keane T, Kelly A. 2010. The assessment of embodied energy in typical reinforced concrete building structures in Ireland. Energy and Buildings 42: 735-744.

Goldin I, Winters LA. 1995. The Economics of Sustainable Development. University of Cambridge Press: Cambridge.

Greene D. 2005. Green building. Environment Design Guide, DES 25.

Guggemos AA, Horvath A. 2005. Comparison of environmental effects of steel and concrete framed buildings. Journal of Infrastructure Systems 11: 93-101.

Hasegawa T. 2003. Environmentally Sustainable Buildings-Challenges and Polocies. (OECD) Organisation for Economic Co-Operation and Development: Frane.

Hes D, Bates M. 2003. Concrete and sustainability—supporting environmentally responsible decision making. Environment Design Guide, PRO 31.

Honey BG, Buchanan AH. 1992. Environmental Impacts of the New Zealand Construction Industry. University of Canterbury: New Zealand.

Hood D. 2004. Implementing energy efficiency and ESD from a development perspective. Environment Design Guide, GEN 60. Q14

Intergovernmental Panel on Climate Change (łpec). 2007. GEO 4: Environment for Development. United Nations Environment Programme (UNEP): Malta.

International Union for Conservation of Nature and Natural Resources (Hen). 1980. World Conservation Strategy. International Union for Conservation of Nature and Natural Resources (IUCN): Switzerland.

Jiao Y, Lloyd CR, Wakes SJ. 2012. The relationship between total embodied energy and const of commercial buildings. Energy and Buildings 52: 20-27.

Junnila S, Horvath A, Guggemos AA. 2006. Life-cycle assessment of office buildings in Europe and the United States. Journal of Infrastructure Systems 10: 10-17.

Kates R. 2000. Population and consumption: what we know, what we need to know. Environment 42: 10-19.

Kates R, Parris T, Leiserowitz A. 2005. What is sustainable development? Goals, indicators, values and practice. Environment: Science and Policy for Sustainable Development 47: 8-21.

Kofoworola OF, Gheewala SH. 2009. Life cycle energy assessment of a typical office building in Thailand. Energy and Buildings 41: 1076-1083.

Kua HW, Wong CL. 2012. Analysing the life cycle greenhouse gas emission and energy consumption of a multi-storied commercial building in Singapore from an extended system boundary perspective. Energy and Buildings 51: 6-14.

Langston YL, Langston CA. 2013. Reliability of building embodied energy modelling: an analysis of 30 Melbourne case studies. Construction Management and Economics 26: 147-160.

Lele SM. 1991. Sustainable development: a critical review. World Develoment 19: 607-621.

Lippiatt BC. 1999. Selecting cost effective green building products: BEES approach. Journal of Construction Engineering and Management 125: 448-455.

Marszal AJ, Heiselberg P. 2011. Life cycle cost analysis of a multi-storey residential net zero energy building in Denmark. Energy 36: 5600-5609.

Mebratu D. 1998. Sustainability and sustainable development: historical and conceptual review. Environmental Impact Assessment 18: 493-520.

Miller D, Doh J-H, Peters T. 2013. Optimised design selection and environmental impact assessment of alternate slab construction methods. In: Choi C-K (ed.) The 2013 World Congress on Advances in Structural Engineering and Mechanics. Jeju: Korea.

Mithraratne N, Vale B. 2004. Life cycle analysis model for New Zealand houses. Building and Environment 39: 483-492.

Monahan J, Powell JC. 2011. A comparison of the energy and carbon implications of new systems of energy provision in new build housing in the UK. Energy Policy 39: 290-298.

O'riordan T. 1985. Future directions in environmental policy. Journal of Environment and Planning 17: 1431-1446.

Oka T, Suzuki M, Konnya T. 1993. The estimation of energy consumption and amount of pollutants due to the construction of buildings. Energy and Buildings: 303-311. 
Omar WMSW, Doh J-H, Panuwatwanich K, Miller D. 2013. Assessment of the embodied carbon in precast concrete wall panels using a hybrid life cycle assessment approach in Malaysia. Sustainable Cities and Society 10: 1-11.

Owen C. 2001. Implementing ecologically sustainable development. Environment Design Guide, GEN 40, 9.

Paya-Zaforteza I, Yepes V, Hospitaler A, González-Vidosa F. 2009. $\mathrm{CO}_{2}$-optimization of reinforced concrete frames by simulated annealing. Engineering Structures 31: 1501-1508.

Pulaski MH, Horman MJ, Riley DR. 2006. Construction practices to manage sustainable building knowledge. Journal of Architectural Engineering 12: 83-92.

Pullen S. 2000. Energy assessment of institutional buildings. Proceedings of Annual Conference of the Australia and New Zealand Architectural Science Association (ANZAScA). The University of Adelaide: South Australia.

Ramesh T, Prakash R, Shukla KK. 2010. Life cycle energy analysis of buildings: an overview. Energy and Buildings 42: 1592-1600.

Redclift M. 1987. Sustainable Development: Exploring the Contradictions. New York, Methuen.

Reddy BVV, Jagadish KS. 2003. Embodied energy of common and alternative building materials and technologies. Energy and Q17 Buildings 35: 139-137.

Sartori I, Hestnes A. 2007. Energy use in the life cycle of conventional and low-energy buildings: a review article. Energy and Buildings 39: 249-257.

Sharma A, Saxena A, Sethi M, Shree V, Varun 2011. Life cycle assessment of buildings: a review. Renewable and Sustainable Energy Reviews 15: 871-875.

Shukla A, Tiwari GN, Sodha MS. 2009. Embedied energy analysis of adobe house. Renewable Energy 34: 755 761,

Smith PF. 2005. Architecture in a Climate of Change. Architectural Press: Oxford.

Spreckley, F 1981. Social Audit: a Management Tool for Co-operative Working. Beechwood College Ltd: Leeds.

Standards Association of Australia (Sat). 2010. Australian Standard: Concrete Structures. AS3600-2009. Standards Australia International: Sydney.

Stein R, Serber D, Hannon B. 1976. Energy Use for Building Construction. University of Illinois, Illinois: U.S. Department of Energy.

Stephan A, Crawford RH, Myttenaere KD. 2011. Towards a more holistic approach to reducing the energy demand of dwellings. Procedia Engineering 21: 1033-1041.

Suzuki M, Oka T. 1998. Estimation of life cycle energy consumption and $\mathrm{CO}_{2}$ emission of office buildings in Japan. Energy and Buildings 28: 33-41.

Thormark C. 2002. A low energy building in a life cycle-its embodied energy, energy need for operation and recycling potential. Building and Environment 37: 429-435.

Treloar GJ. 1997. Extracting embodied energy paths from input-output tables: towards an input-output-based hybrid energy analysis method. Economic Systems Research 9: 375-391.

Treloar GJ, Fay R, Ilozor B, Love P. 2001. An analysis of the embodied energy of office buildings by height. Facilities 19: $204-214$.

Treloar GJ, Fay R, Love P, Iyer-Raniga U. 2000. Analysing the life-cycle energy of an Australian residential building and its householders. Building Research and Information 28: 184-195.

Tryzna TC. 1995. A sustainable world. Sacremento: International Union for Conservation of Nature and Natural Resources (IUCN).

Tucker SN, Treloar GJ. Embodied energy in construction and refurbishment of buildings. Buildings and the Environment, Proceedings of International Conference, Garston, UK. Building Research Establishment, 1994; 1-8.

Walker-Morison A, Grant T, Mcalister S. 2007. The environmental impact of building materials. Environment Design Guide, PRO 7.

Winther BN, Hestnes AG. 1999. Solar versus green: the analysis of a Norweigen row house. Solar Energy 5: 387-393.

Wood A. 2007. Sustainability: a new high-rise vernacular? The Structural Design of Tall and Special Buildings 16: 401-410.

World Commission on Environment and Development (1987. Our Common Future, Brundtland GH (ed.). United Nations General Assembly: New York.

Wu HJ, Yuan ZW, Zhang L, Bi J. 2014. Life cycle energy consumption and $\mathrm{CO}_{2}$ emission of an office building in China. The Q22 International Journal of Life Cycle Assessment 17: 105-118.

Yohanis YG, Norton B. 1998. Estimating at the earliest stages of design the financial cost and operational energy requirements of buildings. Journal of Financial Management and Property Construction 3: 41-58.

Yohanis YG, Norton B. 2002. Life-cycle operational and embodied energy for a generic single storey office building in the UK. Energy 27: 77-92.

Yohanis YG, Norton B. 2006. Including embodied energy considerations at the conceptual stage of building design. Procedings of the Institution of Mechanical Engineers 220: 271-288.

Zahedi A. 2010. Australian renewable energy progress. Renewable and Sustainable Energy Reviews 14: 2208-2213.

Zuo J, Read B, Pullen S, Shi Q. 2012a. Achieving carbon neutrality in commercial building developments—perceptions of the construction industry. Habitat International 36: 278-286.

Zuo J, Zillante G, Wilson L, Davidson K, Pullen S. 2012b. Sustainability policy of construction contractors: a review. Renewable and Sustainable Energy Reviews 16: 3910-3916. 


\section{Author Query Form}

\section{Journal: The Structural Design of Tall and Special Buildings}

\section{Article: tal_1172}

Dear Author,

During the copyediting of your paper, the following queries arose. Please respond to these by annotating your proofs with the necessary changes/additions.

- If you intend to annotate your proof electronically, please refer to the E-annotation guidelines.

- If you intend to annotate your proof by means of hard-copy mark-up, please refer to the proof markup symbols guidelines. If manually writing corrections on your proof and returning it by fax, do not write too close to the edge of the paper. Please remember that illegible mark-ups may delay publication.

Whether you opt for hard-copy or electronic annotation of your proofs, we recommend that you provide additional clarification of answers to queries by entering your answers on the query sheet, in addition to the text mark-up.

\begin{tabular}{|c|c|c|}
\hline Query No. & Query & Remark \\
\hline Q1 & AUTHOR: Please supply authors' biographies. & \\
\hline Q2 & $\begin{array}{l}\text { AUTHOR: Knowledge has undoubtedly advanced; however, } \\
\text { population-driven consumption continues to drive large-scale } \\
\text { development related environmental impacts (Kates, 2000, } \\
\text { Kates et al., 2005). This sentence has been modified for } \\
\text { clarity. Please check and confirm for correctness. }\end{array}$ & \\
\hline Q3 & AUTHOR: Please check if the suggested short title is okay. & \\
\hline Q4 & $\begin{array}{l}\text { AUTHOR: This was a result of the following variables: system } \\
\text { boundaries, building/material life spans and life cycle analysis } \\
\text { (LCA) techniques. This sentence has been modified for } \\
\text { clarity. Please check and confirm for correctness. }\end{array}$ & \\
\hline Q5 & $\begin{array}{l}\text { AUTHOR: "Wu et al., } 2012 \text { " is cited in text but not given in the } \\
\text { reference list. Please provide details in the list or delete the } \\
\text { citation from the text. }\end{array}$ & \\
\hline Q6 & $\begin{array}{l}\text { AUTHOR: "Suzuki et al., } 1995 \text { " is cited in text but not given in } \\
\text { the reference list. Please provide details in the list or delete the } \\
\text { citation from the text. }\end{array}$ & \\
\hline Q7 & $\begin{array}{l}\text { AUTHOR: "Venkatarama \& Jagadish, } 2003 \text { " is cited in text } \\
\text { but not given in the reference list. Please provide details in } \\
\text { the list or delete the citation from the text. }\end{array}$ & \\
\hline Q8 & $\begin{array}{l}\text { AUTHOR: "Shukla et al., } 2008 \text { " is cited in text but not given in } \\
\text { the reference list. Please provide details in the list or delete the } \\
\text { citation from the text. }\end{array}$ & \\
\hline
\end{tabular}




\begin{tabular}{|c|c|c|}
\hline Query No. & Query & Remark \\
\hline Q9 & $\begin{array}{l}\text { AUTHOR: "Langston \& Langston, } 2008 \text { " is cited in text but } \\
\text { not given in the reference list. Please provide details in the } \\
\text { list or delete the citation from the text. }\end{array}$ & \\
\hline Q10 & $\begin{array}{l}\text { AUTHOR: Building life, system boundary, building use type, } \\
\text { structural material and geographical location where all things } \\
\text { are considered to influence the contribution were calculated } \\
\text { as a result of EE and OE. This sentence has been modified } \\
\text { for clarity. Please check and confirm for correctness. }\end{array}$ & \\
\hline Q11 & $\begin{array}{l}\text { AUTHOR: This variability was seen between studies. This } \\
\text { sentence has been modified for clarity. Please check and } \\
\text { confirm for correctness. }\end{array}$ & \\
\hline Q12 & AUTHOR: Please provide city location. & \\
\hline Q13 & $\begin{array}{l}\text { AUTHOR: If this reference has now been published online, } \\
\text { please add relevant year/DOI information. If this reference } \\
\text { has now been published in print, please add relevant volume/ } \\
\text { issue/page/year information. }\end{array}$ & \\
\hline Q14 & $\begin{array}{l}\text { AUTHOR: If this reference has now been published online, } \\
\text { please add relevant year/DOI information. If this reference } \\
\text { has now been published in print, please add relevant volume/ } \\
\text { issue/page/year information. }\end{array}$ & \\
\hline Q15 & AUTHOR: Please provide volume. & \\
\hline Q16 & $\begin{array}{l}\text { AUTHOR: If this reference has now been published online, } \\
\text { please add relevant year/DOI information. If this reference } \\
\text { has now been published in print, please add relevant volume/ } \\
\text { issue/page/year information. }\end{array}$ & \\
\hline Q17 & $\begin{array}{l}\text { AUTHOR: Reference "Reddy \& Jagadish (2003)" is not cited } \\
\text { in the text. Please indicate where it should be cited; or delete } \\
\text { from the reference list. }\end{array}$ & \\
\hline Q18 & AUTHOR: please provide initial for Varun. & \\
\hline Q19 & $\begin{array}{l}\text { AUTHOR: Reference "Shukla et al. (2009)" is not cited in the } \\
\text { text. Please indicate where it should be cited; or delete from the } \\
\text { reference list. }\end{array}$ & \\
\hline Q20 & $\begin{array}{l}\text { AUTHOR: If this reference has now been published online, } \\
\text { please add relevant year/DOI information. If this reference } \\
\text { has now been published in print, please add relevant volume/ } \\
\text { issue/page/year information. }\end{array}$ & \\
\hline Q21 & $\begin{array}{l}\text { AUTHOR: Please check capturing of book title if correct, if not } \\
\text { please provide book title. }\end{array}$ & \\
\hline Q22 & $\begin{array}{l}\text { AUTHOR: Reference "Wu et al. (2011)" is not cited in the text. } \\
\text { Please indicate where it should be cited; or delete from the } \\
\text { reference list. }\end{array}$ & \\
\hline
\end{tabular}


Required software to e-Annotate PDFs: Adobe Acrobat Professional or Adobe Reader (version 7.0 or above). (Note that this document uses screenshots from Adobe Reader $\mathrm{X}$ )

The latest version of Acrobat Reader can be downloaded for free at: http://get.adobe.com/uk/reader/

Once you have Acrobat Reader open on your computer, click on the Comment tab at the right of the toolbar:

닙

This will open up a panel down the right side of the document. The majority of tools you will use for annotating your proof will be in the Annotations section, pictured opposite. We've picked out some of these tools below:

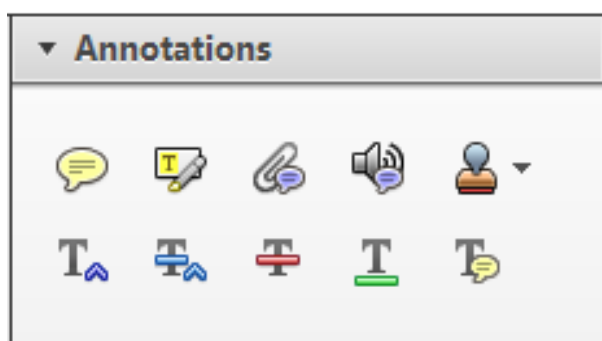

1. Replace (Ins) Tool - for replacing text.

Strikes a line through text and opens up a text box where replacement text can be entered.

How to use it

- Highlight a word or sentence.

- Click on the Replace (Ins) icon in the Annotations section.

- Type the replacement text into the blue box that appears.

Idard tramework for the analysis of $\mathrm{m}$ icy-Nevertheless, it also led to exog،

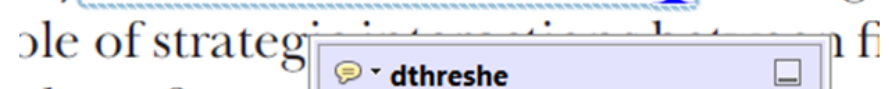
\begin{tabular}{l|l|l} 
aber of comp & 08/06/2011 15:58:17 & 0
\end{tabular} is that the $\mathrm{s} 1 \overline{\text {, which led }}$ of nain compo: be level, are exc nc

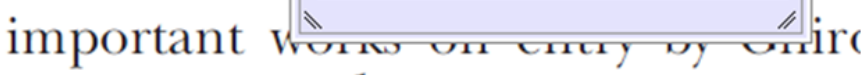
M heneferth) ${ }^{1}$ we anen the "hlarl $\mathrm{h}$

3. Add note to text Tool - for highlighting a section to be changed to bold or italic.

T Highlights text in yellow and opens up a text box where comments can be entered.

How to use it

- Highlight the relevant section of text.

- Click on the Add note to text icon in the Annotations section.

- Type instruction on what should be changed regarding the text into the yellow box that appears.

namic responses of mark ups ent with the VAR evidence

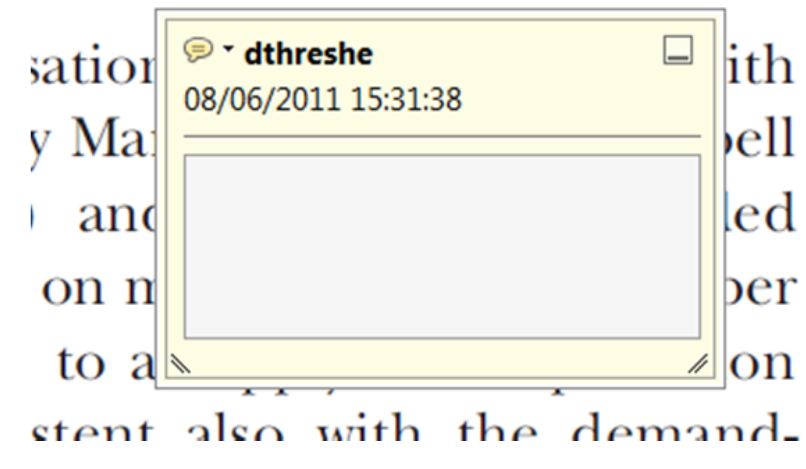

2. Strikethrough (Del) Tool - for deleting text.

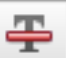

Strikes a red line through text that is to be deleted.

How to use it

- Highlight a word or sentence.

- Click on the Strikethrough (Del) icon in the Annotations section.

there is no room tor extra prohts al s ups are zero and the number of ret) values are not determined by Blanchard and Kiyotaki (1987), sfect competition in general equilil ts of aggregate demand and supply lassical framework assuming monol sen an evorenous number of firms

4. Add sticky note Tool - for making notes at specific points in the text.

Marks a point in the proof where a comment needs to be highlighted.

How to use it

- Click on the Add sticky note icon in the Annotations section.

- Click at the point in the proof where the comment should be inserted.

- Type the comment into the yellow box that appears.

iaisu airu suppiy sisuks. hivsl ui

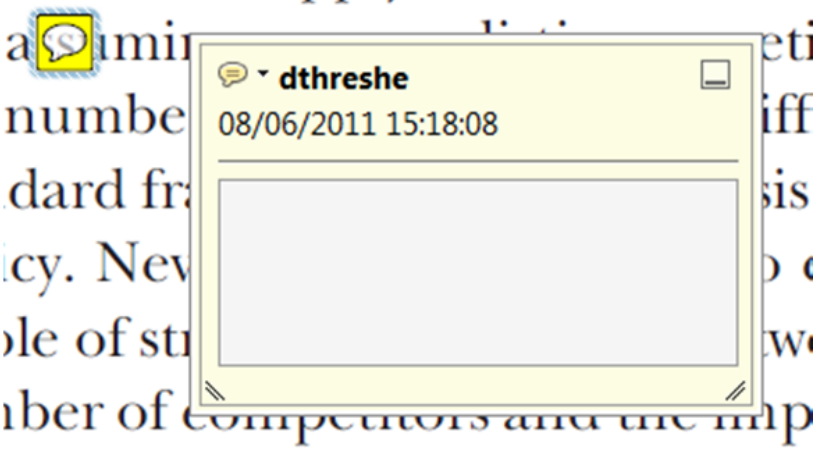

is that the structure of the sectc. 
5. Attach File Tool - for inserting large amounts of text or replacement figures.

Inserts an icon linking to the attached file in the appropriate pace in the text.

How to use it

- $\quad$ Click on the Attach File icon in the Annotations section.

- Click on the proof to where you'd like the attached file to be linked.

- Select the file to be attached from your computer or network.

- Select the colour and type of icon that will appear in the proof. Click OK.

E N D

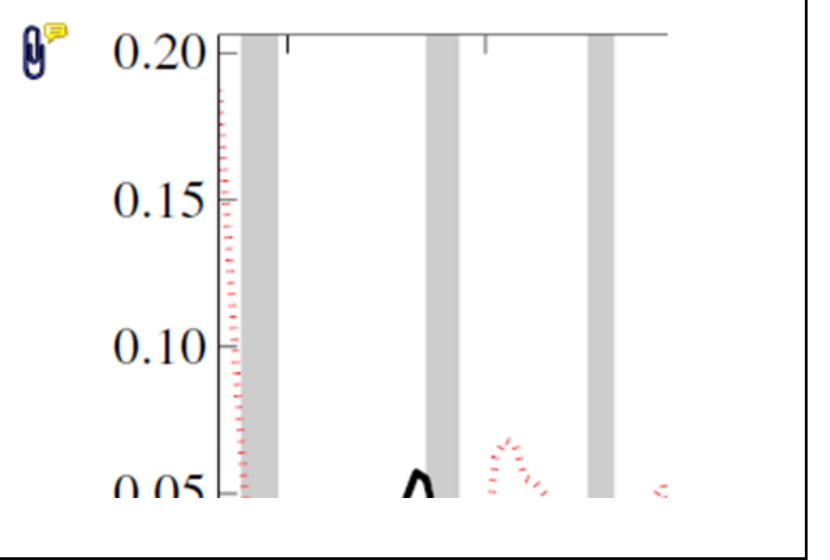

6. Add stamp Tool - for approving a proof if no corrections are required.

- Inserts a selected stamp onto an appropriate place in the proof.

\section{How to use it}

- $\quad$ Click on the Add stamp icon in the Annotations section.

- Select the stamp you want to use. (The Approved stamp is usually available directly in the menu that appears).

- Click on the proof where you'd like the stamp to appear. (Where a proof is to be approved as it is, this would normally be on the first page).

)t the Dusiness cycie, starting with the on perfect competition, constant ret

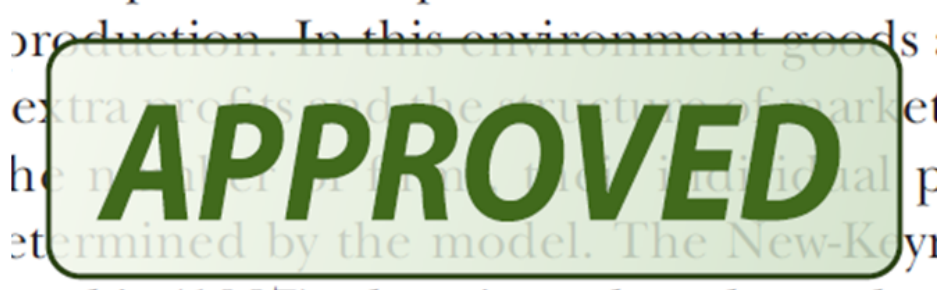
otaki (1987), has introduced produc general equilibrium models with nomin:

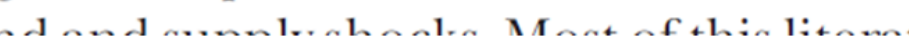

- Drawing Markups

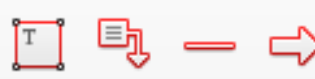

$0 \bigcirc \sqrt{6} \otimes$

\section{How to use it}

- Click on one of the shapes in the Drawing Markups section.

- Click on the proof at the relevant point and draw the selected shape with the cursor.

- To add a comment to the drawn shape, move the cursor over the shape until an arrowhead appears.

- Double click on the shape and type any text in the red box that appears.
7. Drawing Markups Tools - for drawing shapes, lines and freeform annotations on proofs and commenting on these marks.

Allows shapes, lines and freeform annotations to be drawn on proofs and for comment to be made on these marks.

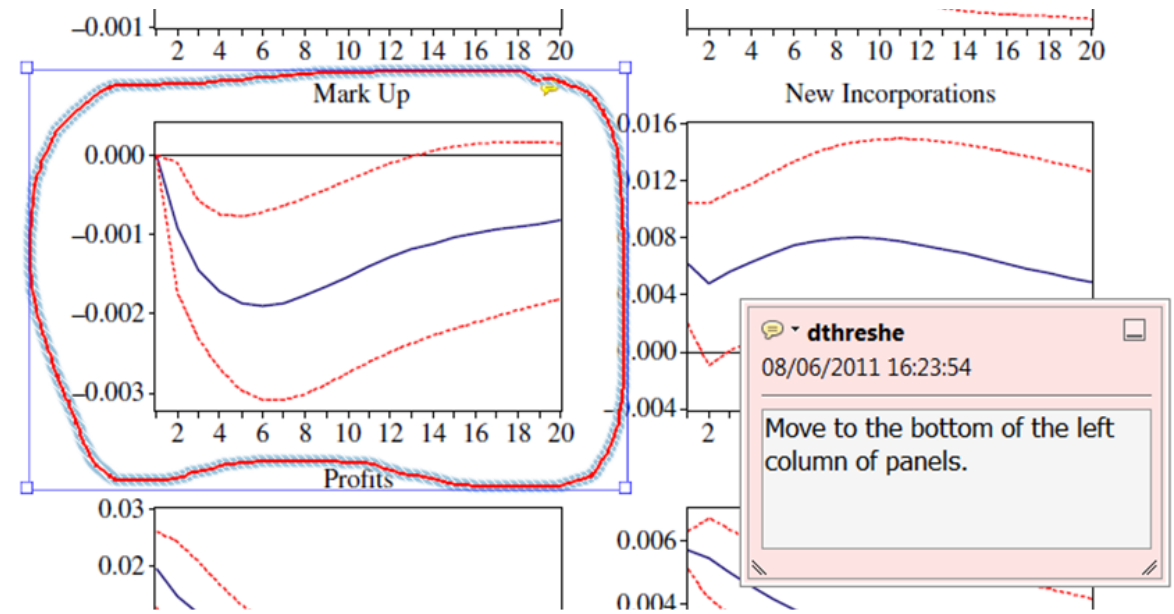

For further information on how to annotate proofs, click on the Help menu to reveal a list of further options:

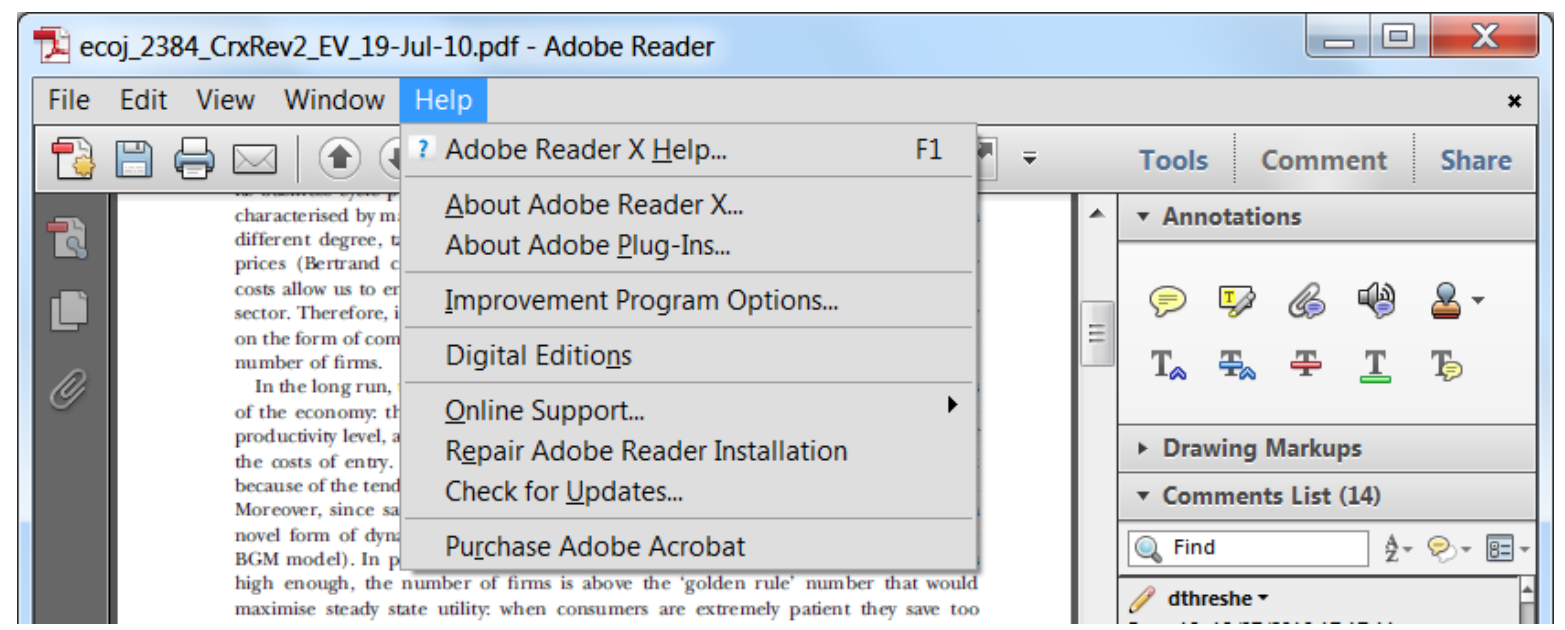

